\title{
POPULAR CULTURE IN (A) NUTSHELL: IAN MCEWAN'S MODERN HAMLET
}

\begin{abstract}
Even though it is difficult to reach a full definition of popular culture, it is generally said that whenever people watch popular films, read tabloids or wear jeans, they actively participate in creating both meaning and pleasure within a certain social structure, thus reflecting their popular tastes and concerns. Hamlet is one of those timeless characters who manages to resist leaving popular culture, and Ian McEwan's latest novel - Nutshell (2016) - contributes to this fact as well. A master of storytelling, McEwan deploys a foetus, the contemporary unborn Hamlet, as his narrator, allowing this character the capability for not only critical judgement and analysis, but also the consumption of popular products (though not a direct one). The aim of this paper is to explore the complicated interpersonal relations and questions of identity with the help of the elements of popular culture found in the text, that way providing an insight into the present state of culture and society (and there is indeed "something rotten" in the world of McEwan's protagonists), as well as pointing out the importance of (analysing) popular culture itself and its elements within the field of cultural studies.
\end{abstract}

Key words: popular culture, elements of popular culture, Nutshell, Ian McEwan, Hamlet

\section{Introduction}

Oh, God, I could be bounded in a nutshell and count myself a king of infinite space - were it not that I have bad dreams. Shakespeare, Hamlet (McEwan 2016: 1)

Ian McEwan's short, but captivating novel - Nutshell - was published in 2016, on the $400^{\text {th }}$ anniversary of Shakespeare's death and, quite interestingly, the author deployed a contemporary Hamlet-like character to retell the original story (though) in a modern setting and entirely modern way. Likewise, something is rotten in our present state of Denmark, represented by a decaying Georgian town house in central London, where we get to know our main characters - Hamlet's mother (Ger-)Trudy who has

${ }^{*}$ PhD candidate, Faculty of Philology, University of Belgrade, Studentski trg 3, 11000 Belgrade; email: jocika_89@yahoo.com 
an affair with Hamlet's hideous uncle Claude(-ius), and last but not least, Hamlet's father John. What is amusing here is that we follow the plot in reverse - our Hamlet wonders whether to be or not to be born, we first see John's life and then move on to his ghost, while everything begins in silence, but ends in complete chaos (Clanchy2016). Hamlet is generally regarded as one of those timeless characters who simply refuses to leave popular culture - so far, he has been an inspiration to some novels, such as John Updike's Gertrude and Claudius, or Iris Murdoch's The Black Prince; he was even given the voice of a lion in Disney's animated film The Lion King. However, never before was he given the voice and the perspective of a foetus like in this book. In one of his interviews, McEwan himself pointed out the fact that part of the entertainment of writing the novel was to discover how the world is revealed to a foetus in two weeks away from being born, who cannot see anything, but is able to hear and speculate a great deal from his tiny and restricted point of view, which nevertheless reveals a lot to the readers (McEwan 2016). This now brings us ideally to the discussion about and analysis of popular culture and its elements.

Although it is rather difficult to put the definition of popular culture in a nutshell (to use the pun), it is possible to give an outline of "the general conceptual landscape" of this "melting pot of confused and contradictory meanings" (Storey 2009: 1). Seldom do we think about the way we all participate in popular culture, and in fact, it takes place on a regular basis whenever we watch television or "popular block buster movies", read "sensational tabloid press" or "trashy popular novels", or whenever we spend time in shopping malls, Disneyworld or any other place offered to us by the capitalist system itself (Fiske 2010: 141). Despite the aforementioned, popular culture is regarded not as consumption, but as "culture - the active process of generating and circulating meanings and pleasures within a social system"; it is made by the people "at the interface between the products of the culture industries and everyday life", it "stems from within, from below, not from above" (Fiske 2010: 19, 21). As Fiske (2010: 21) himself has emphasised, "[p]eople can, and do, tear their jeans", that way defying "the forces of domination", and it is precisely their "relation to and experience of the objects and the commodities which fuel" our further analysis (McRobbie 2005: 36).

\section{Nutshell's manifold excessiveness}

SO HERE I AM, upside down in a woman. Arms patiently crossed, waiting, waiting and wondering who I'm in, what I'm in for. My eyes close nostalgically when I remember how I once drifted in my translucent body bag, $[\ldots]$ colliding gently against the transparent bounds of my $[\ldots]$ confiding membrane that vibrated with, even as it muffled, the voices of conspirators in a vile enterprise. That was in my careless youth. Now, 
fully inverted, not an inch of space to myself, [...] my thoughts as well as my head are fully engaged. I've no choice, my ear is pressed all day and night against the bloody walls. I listen, make mental notes, and I'm troubled. I'm hearing pillow talk of deadly intent and I'm terrified by what awaits me, by what might draw me in. (McEwan 2016: 1)

Not only do we have a striking opening line, but also an excessive, and almost sensational, introduction, narrated by a well-spoken, highbrow foetus that grips our attention from the very first moment and makes us think. Popular culture tends to that, since, as Fiske (2010: 92) has noted, "[e]xcessiveness is meaning out of control, [i.e.] meaning that exceeds the norms of ideological control". Once exceeded, norms "lose their invisibility", together with "their status as natural common sense", and are then "brought out into the open agenda" (Fiske 2010: 92). We are free and even provoked to make some comments and "mock the conventional" while simultaneously noticing how everything which fails to accord with the previously mentioned normal ideology reveals the real state of affairs (Fiske 2010: 92). For this very reason, it can be said that our unorthodox protagonist represents part of popular culture since he, as a shocking element will make us actively generate meaning out of his every action, statement, depiction, thought, and last, but not least, his consumption of popular products.

Our modern-day prince spends his days living in a seven-million-pound-worth family mansion whose "six thousand aching square feet" he describes as being in "a rotten state", "filthy", "peeling, crumbling, dilapidated" (McEwan 2016: 12). While reading the novel, one can clearly notice that Nutshell's Elsinore castle is full of elements of popular culture and that precisely McEwan's excessive usage of these elements sends a clear message that we should pay attention to their rich semiosis:

Plaster dust, a smell of death [...] The floor above, bedroom and bathroom, chaos of an intimate kind, the bed itself a tangle of lust and broken sleep, the floor strewn or piled with Trudy's discarded clothes, the bathroom likewise with lidless pots, unguents, and dirty underwear. I wonder what disorder tells suspicious eyes. It can't be morally neutral. A contempt for things, for order, cleanliness, must lie on a spectrum with scorn for laws, values, for life itself. What is a criminal but a disordered spirit? (McEwan 2016: 179)

This is neither a plain rebellion against the dominant ideology nor a pleasure in creating one's own popular meaning and identity. This extract provides something more for the analysis. The strong, shocking image that we get seizes our attention 
instantaneously. We have the house that resembles everything but a warm family home which is being prepared for the birth of a baby by happy parents. For the entire situation, the foetus itself says: “...no preparations have been made for my arrival, no clothes, no furniture, no compulsive nest-making. I've never knowingly been in a shop with my mother. The loving future is a fantasy" (McEwan 2016:132). Even though he is not born yet, our baby Hamlet is burdened by the lack of love that he feels and the bleak future that awaits him. Besides that, readers are offered a frame of reference "for the construction of [both] collective and personal identities" of the main characters, which we are prone to judge and analyse in a rather negative manner (Strinati 2004: 227). What is more than evident here is that all these depictions testify about the disrupted family relations, a dysfunctional marriage and a broken home, as well as the inappropriateness of Trudy's affair with her brother-in-law. On top of that, readers can see people who are definitely dissatisfied with their own lives, and are on the verge of becoming destructive, both to themselves as well as others. Moreover, since family is regarded as the basic unit of society, it becomes clear that there is something really wrong with society and that its moral is at quite a low level. There are other interesting parts of the book that make good parallels with the current state of culture and society:

We're safely on the ground floor, among the busy morning hum of flies that cruise the hallway's garbage. To them the united plastic bags rise like shining residential towers with rooftop gardens. The flies go there to graze and vomit at their ease. Their general bloated laziness invokes a society of mellow recreation, communal purpose, mutual tolerance. This somnolent, non-chordate crew is at one with the world, it loves rich life in all its putrefaction. Whereas we're a lower form, fearful and in constant discord. (McEwan 2016: 77-78)

What else can be noticed in this extract is that the entire setting is rather dark and gloomy - the plastic (garbage) bags as the element of popular culture, then flies swarming around decomposing items, as well as the lack of cleanliness and any kind of order, all seem ominous and in consent with Trudy and Claude's current state of mind as well as actions. They are even subordinated to the lower form of life and turn out to be far more meagre than those, as McEwan calls them, bloated lazy insects.

\section{McEwan's modern Hamlet-like characters}

In our everyday lives, we are constantly being exposed to clichés, those common sense articulations of the dominant ideology that "bear ideological norms", which makes them "such powerful constructors and circulators of common sense" (Fiske 2010: 95). 
However, according to some popular culture theorists, they have greater cultural uses - they can work "to expose the gap between that ideology and everyday experience" (Fiske 2010: 95). For instance, Trudy escapes the typical representation of a young housewife, a loving married woman and a caring mother who is expecting a child. Her lover Claude even mocks her at one point and reveals the irony of Trudy's character: "He's at the sink, rinsing crusty cups, doing as he's told. She's impervious to his tone and adds, 'We should tidy this place up.' He grunts. A hopeless notion. Good wife Trudy wants to greet her husband with a tidy kitchen" (McEwan 2016: 80). As we could have seen it in some of the previously quoted passages, even the unborn baby exposes his mum to criticism, since she never seems to fit the image of a perfect mother either:

I'd like to think that her purpose out here is to generate vitamin D for my bone growth, that she has turned down the radio the better to contemplate my existence, that the hand caressing the place where she believes my head to be is an expression of tenderness. But she may be working on her tan and too hot to listen to the radio drama about the Mughal emperor Aurangzeb, and is merely soothing with her fingertips the bloated discomfort of late pregnancy. In short, I am uncertain of her love. (McEwan 2016: 32)

And the readers are almost of the same opinion. In most cases, Trudy behaves as if she wasn't pregnant. She indulges herself in a number of different ways - she wears clothes which make her feel comfortable and desirable and she also enjoys a good glass (or a couple more) of wine while sunbathing on the balcony outside John's library: "Trudy is barefoot, in bikini top, and brief denim shorts that barely allow me. Pink-framed, heart-shaped sunglasses and a straw hat top this confection. I know this because my uncle - my uncle! - asked her on the phone to tell him what she was wearing. Flirtatiously, she obliged" (McEwan 2016: 31). Another thing that grips our attention is her looks, which is, in many ways, being eroticised in numerous passages throughout the novel. Trudy resembles Lolita; she is corrupted and corrupting, seen from a new, as some would say perverse, point of view: "A young woman, gut and breasts swollen to breaking [...] the gravidly ripe twenty-eight-year-old, youngly slumped (I insist on the adverb) across the table, blonde and braided like a Saxon warrior, beautiful beyond realism's reach, slender but for me, near naked, sunnily pink on the upper arms" (Clanchy 2016; McEwan 2016: 47, 50). All the mentioned elements are gradually assembled together to show us her true identity. There are even some critics who have noticed a clash in Trudy's description. They have gone so far as to say that she somehow seems disconnected from the contemporary: a woman born in the 80 s who has never thought of work or heard of everyday sexism, who 
prefers calling Claude on the phone to texting, who doesn't use the Internet for social networks or Google searches. Were it not for earbuds or podcast lectures, they simply wouldn't feel her ties to the $21^{\text {st }}$ century (Clanchy 2016).

McEwan's Hamlet is an equally complex character like his mother Trudy. Even though he is not born yet, we get to know a lot about his identity during his passive consumption of popular products. From the very first moment, we meet one highly eloquent narrator who explains his acquired knowledge with active listening sessions. During their listening time, the narrator and his mother Trudy actively participate in popular culture, i.e. in creating both meaning and pleasure within their own social structure, thus reflecting their popular tastes and concerns. The way they get informed and educated - via the radio, podcast lectures, TV and audio books - tells us that they want that freedom to choose what they want to listen and when they want to listen to it. The baby even occasionally takes the initiative and, on top of that, shows different and a bit more discerning taste from his mother, as the following extracts reveal: "How is it that I, not even young, not even born yesterday, could know so much, or know enough to be wrong about so much? I have my sources, I listen. My mother, Trudy, when she isn't with her friend Claude, likes the radio and prefers talk to music. Who, at the Internet's inception, would have foreseen the rise and rise of radio, or the renaissance of that archaic word, 'wireless'? (McEwan 2016: 4)". The foetus continues his talk:

In the middle of a long, quiet night I might give my mother a sharp kick. She'll wake, become insomniac, reach for the radio. Cruel sport, I know, but we are both better informed by the morning. And she likes podcast lectures, and self-improving audio books - Know Your Wine, in fifteen parts, biographies of seventeenth-century playwrights, and various world classics. James Joyce's Ulysses sends her to sleep, even as it thrills me. [...] Even television conveys most of its meagre utility by sound. (McEwan 2016: 4, 5)

Baby Hamlet even shares Trudy's wine snobbery and love towards consumption of popular products, though (again paradoxically) with a bit more refined taste:

We're sharing a glass, perhaps a bottle, of Marlborough Sauvignon Blanc. Not my first choice, and for the same grape and a less grassy taste, I would have gone for a Sancerre, preferably from Chavignol [...] But [...] it's in us, and I'm happier than I've been for two days. Trudy cools our wine with plastic cubes of frozen ethanol. I've nothing against that [...] After a piercing white, a Pinot Noir is a mother's soothing hand. Oh, to 
be alive while such a grape exists! A blossom, a bouquet of peace and reason. (McEwan 2016: 31-32, 52)

Whereas it seems that Trudy wants to silence her conscience and sink into oblivion because she is dissatisfied with the present situation, not to mention that she is troubled by what she is about to do - and that is, kill her husband, the foetus on the other hand seems to seek comfort due to his worries about the world he is going to be born into. Everything starts with the epigraph to this novel, which comes directly from Shakespeare's Hamlet -quoted in the introductory part of this research paper; those bad dreams (mentioned there) are the news about the world he is about to meet, which he sees as rather cold, with a disrupted set of values as well as with the evidently poor state of society that doesn't care much about its people. For it, Hamlet says: "From here it seems unkind, careless of life, of lives. The news is brutal, unreal, a nightmare we can't wake from. I listen with my mother, rapt and glum [...] Barrels used as bombs over cities, children used as bombs in marketplaces. We heard from Austria about a locked roadside truck and seventy-one migrants left to panic, suffocate and rot [...] These are new times. Perhaps they're ancient" (McEwan 2016: 84).

Another criticism against society is John's failure and Claude's success in life. We come to realise that completely wrong qualities are (being) appreciated. Unlike his brother, John is presented as a man who possesses a romantic personality, which is expressed precisely with the help of certain elements of popular culture. As we have learned, he finds joy in small things, such as writing a poem or buying smoothies for his pregnant wife, just to indulge her: "Sometimes he brings her smoothies from his favourite place on Judd Street. He has a weakness for these glutinous confections that are supposed to extend his life" (McEwan 2016: 10). Since he is the owner of a publishing house, his artistic side comes to the surface as well: "The pencil's back in my father's hand, a cigarette's in the other. He'll go on with the only work that matters, proofing poems for the printers, and won't look up until it's six and time for a whisky and water" (McEwan 2016: 37-38). Hamlet's father takes pride in his Cairncross Press, and this is really something that should be praised and appreciated. However, the fact that John's business is impoverished now, accompanied by his good-hearted nature doesn't (ironically) bring him much good. All of this actually enables Claude to look down on his own brother and even makes the plot to kill him and take (over) his house far more easily. As we learn along the way, John doesn't even live in his childhood home with his wife and his unborn son, but spends his days living in "three mean rooms in Shoreditch" on which he has "a six-month lease", while having to put up with Trudy and Claude's affair (McEwan 2016: 11).

And "who is this Claude? [...] I heard it once and took note: the dull-brained yokel" (McEwan 2016: 20). The satanic younger brother who is a real estate developer 
is shown as a pretty vain and shallow person, who cares only about material things, which he uses to build himself some pleasurable identity:

[D]ull to the point of brilliance, vapid beyond invention, his banality as finely wrought as the arabesques of the Blue Mosque. Here is a man who whistles continually, not songs but TV jingles, ringtones [...] who washes his private parts at the basin where my mother washes her face. Who knows only clothes and cars. And has told us a hundred times that he would never buy or even drive such, or such, or a hybrid or a...or... That he only buys his suits in this, no, that Mayfair street, his shirts in some other, and socks from, he can't recall...If only...but. No one else ends a sentence on a 'but'. (McEwan 2016: 20)

Claude fits perfectly in the cliché of "men as slobby, selfish jocks" of patriarchal capitalism (Fiske 2010: 95). He cares solely of himself and his well-being, while constantly expressing self-absorption throughout the novel: “... Claude is a man who prefers to repeat himself. A man of riffs. On shaking hands with a stranger - $[\ldots]$ he'll say, 'Claude, as in Debussy.' How wrong he is. This is Claude as in property developer who composes nothing, invents nothing. [...] Vibrating the air a second time with his thought is integral to his pleasure" (McEwan 2016: 5). Claude doesn't strain his brain a lot and thinks only about how to satisfy any need that he has at some moment. Even his intercourse with Trudy is devoid of any kind of emotion: "His knees depress the unfaithful mattress that lately held my father. [...] Enter Claude. [...] no kisses, nothing touched or fondled, [...] [o]nly the accelerating creak of the bed, $[\ldots]$ then, after her final rising-falling shout-and-shudder [...] [e]xit Claude" (McEwan 2016: 23). The bed and the mattress as the elements of popular culture both reveal these lovers' intimacy, deprived of tenderness, affection, let alone love (of any kind). Thus, after assembling all the images together, the readers tend to see Claude as a not-thathighly-intelligent person, with quite a low moral and fundamentally bad character; he is so jealous of his older brother that he reaches a decision to take everything away from him - his wife, his unborn child, his house, and even his life.

\section{Conclusion}

I think I see the entire world in this face. Beautiful. Loving. Murderous. [...] And I'm thinking about our prison cell - I hope it's not too small - and beyond its heavy door, worn steps ascending: first sorrow, then justice, then meaning.

The rest is chaos. (McEwan 2016: 198-199) 
All in all, after revisiting Shakespeare's classic in Ian McEwan's altered version, we can see that not even after 400 years do some plots and characters lose in their appeal and attractiveness. Not to mention that something is still rotten in our modernday world, as the analysis itself has revealed. As for popular culture, it definitely provides enough material for the complicated field of cultural studies to explore people's everyday experiences. This is important because, that way, we get an insight into individuals' identities, their lives, ways of functioning within a society, as well as the general condition of that society and culture they belong to. Nutshell's characters prove (once again) McEwan's position as a master of storytelling who is capable of describing the present state - corruption, envy, as well as "doom and gloom"-in such a fantastic way that grips readers' attention completely from the first to the last page of the novel. In the very end, it can be said that if babies can really hear everything and experience many things while they are still in the womb - like McEwan's Hamlet can - perhaps it is no wonder they always come out screaming.

\section{References}

Clanchy, K. (2016). Nutshell by Ian McEwan review - An Elegiac Masterpiece. The Guardian. (26 May 2019) <https://www.theguardian.com/books/2016/aug/27/ nutshell-by-ian-mcewan-review>.

Fiske, J. (2010). Understanding Popular Culture. $2^{\text {nd }}$ edition. London and New York: Routledge.

Ian McEwan discusses his new novel, Nutshell. (2016). (5 November 2018) <https:// www.youtube.com/watch? $\mathrm{v}=$ FawXcatzjsE $>$.

McEwan, I. (2016). Nutshell. London: Vintage.

McRobbie, A. (2005). Postmodernism and Popular Culture. London and New York: Routledge.

Storey, J. (2009). Cultural Theory and Popular Culture: An Introduction. $5^{\text {th }}$ edition. London: Pearson Longman.

Strinati, D. (2004). An Introduction to Theories of Popular Culture. $2^{\text {nd }}$ edition. London and New York: Routledge. 